\title{
Custo Social da Degradação da Qualidade Hídrica para o Abastecimento Público
}

\author{
Raquel Pompermayer ${ }^{1}$, Humberto Angelo ${ }^{2}$, Alexandre Nascimento de Almeida ${ }^{3}$
}

${ }^{1}$ Instituto de Ciências, Engenharia e Tecnologia, Universidade Federal dos Vales do Jequitinhonha e Mucuri - UFVJM, Teófilo Otoni/MG, Brasil

${ }^{2}$ Faculdade de Engenharia Florestal, Universidade de Brasília - UnB, Brasilia/DF, Brasil

${ }^{3}$ Faculdade UnB de Planaltina - FUP, Universidade de Brasília - UnB, Brasília/DF, Brasil

\section{RESUMO}

Este trabalho propõe a determinação do custo social da degradação da qualidade hídrica em bacias hidrográficas de captação urbana do Distrito Federal, Brasil. Procurou-se elaborar um procedimento de valoração econômica que permita dimensionar a magnitude dos impactos da perda da cobertura florestal sobre o bem-estar social. Os impactos da degradação da qualidade hídrica foram estimados em duas classes de consumidores residenciais do sistema público de abastecimento de água. Na categoria popular (baixa renda), o custo social foi estimado em $\mathrm{R} \$ 7,0$ milhões por ano, o que representou $8,9 \%$ da despesa total de água dos consumidores dessa categoria no período de janeiro de 2003 a dezembro de 2008. Na categoria normal (de renda média a alta) o custo social foi estimado em $\mathrm{R} \$ 12,9$ milhões por ano, o equivalente $6,8 \% \mathrm{da}$ despesa total de água desses consumidores no período estudado.

Palavras-chave: manejo de bacias hidrográficas, valoração ambiental, desmatamento.

\section{Social Cost of Water Quality Degradation for Public Supply}

\begin{abstract}
This paper proposes the evaluation of social cost of water quality degradation in urban reception basins of the Federal District, Brazil. We sought to elaborat a procedure allowing the economic evaluation of the loss of forest coverage impacts on welfare. The impacts of water quality degradation was estimated in two classes of residential consumers of public water supply. In the popular category (low income), the social cost was estimated at $\$ 7.0$ million per year, which represents $8.9 \%$ of total expenditure on water consumers in this category from January 2003 to December 2008. In the regular category (middle and high income) the social cost was estimated at $\$ 12.9$ million per year, the equivalent to $6.8 \%$ of total expenditure with water consumer in the period studied.
\end{abstract}

Keywords: watershed management, environmental valuation, deforestation. 


\section{INTRODUÇÃO}

O desflorestamento tem efeitos negativos sobre os fluxos de água no solo, alterando, particularmente, a qualidade hídrica da bacia hidrográfica. Os impactos do avanço da urbanização sobre os mananciais refletem-se nos custos de tratamento da água, principalmente em bacias pobres em florestas ripárias e cobertura vegetal natural.

A fraca percepção dos benefícios econômicos indiretos proporcionados pela qualidade ambiental é responsável pelas divergências de interesses. Por um lado, a não conversão de florestas em áreas agrícolas e urbanas preserva sua função de provimento de serviços ecossistêmicos imprescindíveis. De outro, impede a sociedade de desfrutar dos benefícios da produção agrícola e das atividades humanas. Assim, na avaliação das implicações de diferentes cursos de ação, não é suficiente apenas reconhecer que os ecossistemas são valiosos para o provimento de bens e serviços. É necessário, ainda, a percepção do quão importante são os serviços ambientais e como o seu valor é afetado pelas diferentes formas de gestão (World Bank, 2004).

Nesse contexto, o desafio consiste na busca de mecanismos de valoração capazes de atender o seguinte requisito: mensurar a magnitude das externalidades (custos ou benefícios) geradas pelas mudanças na qualidade hídrica da bacia hidrográfica. Assim, uma abordagem com aptidão para capturar medidas de valor econômico do serviço ambiental de uso indireto poderia ser implementada para traduzi-lo em termos de custos ou benefícios marginais. Propõe-se, assim, estimar os impactos da degradação do serviço ambiental de provisão de qualidade hídrica sobre o bem-estar dos consumidores residenciais de água.

Nessa perspectiva insere-se o método da produtividade marginal, fundamentado no conceito de excedente econômico para a derivação das curvas de "demanda-benefício" do consumidor e de "oferta-custo" do produtor.

Assim, as investigações foram feitas sob a perspectiva econômica global, isto é, do ponto de vista da sociedade, em que a perda do serviço ambiental de provisão de qualidade hídrica na bacia de captação devido às mudanças na cobertura florestal promove uma redução no nível de bem-estar social. A redução do bem-estar econômico é uma medida do custo social da escassez de qualidade hídrica que incide sobre a população usuária de água do sistema de abastecimento público, após conhecidas as características da curva de demanda e da resposta da empresa monopolística em relação ao preço da água potável ofertada.

\section{MATERIAL E MÉTODOS}

\section{1. Área de estudo}

A área de estudo integra o Distrito Federal (DF), região caracterizada por elevada densidade demográfica, equivalente a $444 \mathrm{hab} / \mathrm{km}^{2}$. A população do Distrito Federal é predominantemente urbana; padrão de ocupação que permanece estável desde sua inauguração. Entretanto, o avanço de condomínios em áreas rurais de conotação urbana tem restringido ainda mais a população rural (CODEPLAN, 2010).

A Companhia de Saneamento de Brasília - CAESB é a empresa responsável pelos serviços de abastecimento de água no Distrito Federal. Segundo informações de 2010, a CAESB atendeu nesse ano 2,3 milhões de pessoas, o que corresponde a $96 \%$ da população urbana do DF. Isso representou um total de $446 \mathrm{mil}$ ligações prediais, que totalizaram 777 mil unidades de consumo. $\mathrm{O}$ abastecimento de água no Distrito Federal é realizado por meio da captação tanto de águas superficiais (majoritária) quanto de águas subterrâneas, sendo que apenas cidades periféricas de Brasília, São Sebastião e Sobradinho, recebem água dessa última origem (CODEPLAN, 2010).

A maioria das bacias hidrográficas de captação é protegida por unidade de conservação, com destaque para o Parque Nacional de Brasília, a Estação Ecológica de Águas Emendadas, a Área de Proteção Ambiental do Descoberto, a Estação Ecológica do Jardim Botânico, entre outras. Com a aprovação do Plano Diretor de Ordenamento Territorial do Distrito Federal - PDOT, as pequenas captações passaram a contar com mais um instrumento legal de proteção, com a instituição das Áreas de Proteção de Mananciais. A CAESB tem atribuição, por meio do decreto-lei n. 524/69, de fiscalização, proteção e conservação das bacias de captação, bem como de participação no processo disciplinar de uso e ocupação da terra a montante das captações (SIAGUA, 2008). 


\subsection{Referencial teórico}

Brown et al. (2008) constataram que as florestas são responsáveis por $53 \%$ da oferta de água nos Estados Unidos. Quando florestas são convertidas para outros usos da terra, seus benefícios tendem a diminuir e, consequentemente, as plantas de tratamento de água sofrem sobrecarga de poluentes (Cretaz \& Barten, 2007).

Ernst (2004) investigou a ligação entre o percentual de cobertura florestal da bacia hidrográfica e os custos de tratamento da água. Freeman et al. (2008) utilizaram um modelo linear para examinar a relação entre qualidade da água, uso da terra e custo de tratamento. Os autores citados constatam relação entre alto nível de turbidez e baixa cobertura florestal. Por outro lado, a cobertura florestal intensa relaciona-se com baixa turbidez. De maneira expressiva, um aumento de $10 \%$ na cobertura florestal resulta em reduções de 3,27\% a $47,47 \%$ nos custos de tratamento da água (Ernst, 2004; Freeman et al., 2008).

Estudos conduzidos pela Trust for Public Land \& The American Water Works Association em 2002 analisam 27 fornecedores de água dos Estados Unidos, revelando que cerca de $50 \%$ a $55 \%$ da variação nos custos de tratamento de água podem ser explicados pelo percentual de cobertura florestal da bacia hidrográfica (Ernst et al., 2004).

Reis (2004) determinou os custos em sistemas de abastecimento com diferentes percentuais de cobertura florestal nas bacias do Rio Piracicaba e do Rio Cotia (estado de São Paulo, Brasil). Uma hierarquização do percentual de cobertura florestal e do custo de produtos químicos nas unidades indicou que os sistemas com menor gasto específico com produtos químicos (inferior a $\mathrm{R} \$ 20$ por $1.000 \mathrm{~m}^{3}$ de água tratada) foram aqueles que apresentavam maiores índices de cobertura florestal (superior a 15\%). Elsin et al. (2010) determinaram os benefícios econômicos da melhoria da qualidade de água para produção de água potável na Bacia do Rio Neuse (Carolina do Norte, Estados Unidos), resultando em reduções nos custos de tratamento, com decréscimos de turbidez de $5 \%$ a $30 \%$.

Com a finalidade de capturar medidas de valor econômico do serviço ambiental proporcionadas pela cobertura florestal para a oferta de água para abastecimento público, recorreu-se aos conceitos da teoria neoclássica do bem-estar social. O método da produtividade marginal reflete diretamente o efeito da qualidade do insumo ambiental (input) sobre o custo de produção de água potável. Isso porque a água naturalmente filtrada pela cobertura vegetal é um substituto direto para outros insumos do processo produtivo, tais como produtos químicos utilizados para filtração e purificação na planta de tratamento.

Várias aplicações do método da variação da produtividade são relatadas na literatura. Pattanayak \& Kramer (2001) combinaram modelagem hidrológica com técnicas econométricas para valorar a mitigação de escassez hídrica prolongada em comunidades agrícolas da Indonésia, em áreas protegida por florestas tropicais. Nunez et al. (2006) e Figueroa \& Pasten (2008) estimaram o valor econômico das florestas temperadas do Chile para o suprimento de água para abastecimento público no qual a vazão da bacia hidrográfica expressou o serviço ecossistêmico de florestas para a oferta de água purificada naturalmente.

Outros estudos têm se concentrado nos efeitos dos sedimentos na qualidade da água para abastecimento. Page et al. (2011) utilizaram o método da produtividade marginal para relacionar os impactos da atividade florestal na produção de sedimentos (uso de estradas) com os custos de tratamento da água.

\subsection{Referencial analítico}

A implementação do método da produtividade marginal consistiu na derivação de medidas de bem-estar resultantes de variações no parâmetro ambiental $\mathrm{S}_{\mathrm{e}}$, representativo do serviço ambiental de proteção da qualidade hídrica. O insumo ambiental é a vazão específica de contribuição da bacia de captação para a provisão de qualidade hídrica nos sistemas produtores. As variações no excedente econômico podem ser interpretadas como uma medida do valor desse serviço ambiental.

As alterações nos benefícios foram determinadas com base numa abordagem conceitual formulada por Freeman \& Harrington (1990). Esses autores derivaram uma medida do nível de bem-estar decorrente de uma variação no fator de produção (S); insumo ambiental que entra diretamente na produção de um único bem. Tal medida pode ser extraída a partir da área delimitada pela curva de demanda e pelas curvas de custo agregado da firma antes e depois de uma mudança da qualidade ambiental. 
O método da variação na produtividade marginal foi desenvolvido por Lynne et al. (1981) para a valoração do serviço de proteção de wetlands (ecossistema natural que fica parcialmente ou até mesmo totalmente inundado durante épocas do ano) para produção pesqueira. Ellis \& Fisher (1987) utilizaram a abordagem proposta por Lynne et al. (1981) para valorar os impactos econômicos de variações na área de wetlands sobre a pesca comercial. Tomando o excedente econômico total como uma medida de valor econômico, Ellis \& Fisher (1987) assumem a hipótese de que um incremento na área da wetland promove aumento na disponibilidade de espécies para pesca e redução nos custos marginais de produção.

A produção de água potável está estreitamente ligada à qualidade da água bruta. Dada a sua natureza, esse insumo ambiental é bastante vulnerável aos padrões de uso e ocupação da terra a montante. Na bacia hidrográfica, a disponibilidade do insumo água bruta depende do papel da cobertura florestal no ciclo hidrológico, na capacidade de armazenamento e na manutenção dos fluxos sazonais e, particularmente, na purificação da água. É consensual adotar a turbidez para mensurar a qualidade da água bruta superficial. Esse parâmetro é uma medida do nível de sedimentos na água, os quais são transportados por escoamento superficial de áreas cultivadas, pastagens e florestas.

Em geral, os serviços ecossistêmicos associados ao fornecimento de qualidade hídrica atendem atividades de uso consuntivo de água (residencial, agrícola e industrial). No intuito de harmonizar dados mensais de custo de tratamento em unidades operacionacionais de tratamento com dados mensais do insumo ambiental representativo da qualidade hídrica, Pompermayer (2012) admitiu a vazão de contribuição para a captação como uma proxy para o parâmetro turbidez. Assim, adotou-se a vazão específica média da bacia de captação como variável ambiental representativa do serviço de proteção da qualidade hídrica.

Nesse caso procurou-se evidenciar como mudanças no insumo ambiental promovem deslocamentos na oferta do bem comercializado (água potável) e, por conseguinte, no nível de bem-estar do consumidor. Para tanto, os custos marginais do insumo ambiental devem refletir, na curva de oferta do bem, as variações nos benefícios econômicos que atingem os usuários de água.
Em geral, os serviços públicos de provimento de água potável comportam grandes instalações, auferindo retornos de escala crescentes e, portanto, caracterizam um monopólio (Hosking \& Preez, 2004). Como a firma monopolística possibilita economia de escala considerável, quantidades maiores são produzidas a custos menores (Pindyck \& Rubinfeld, 2002; Pizaia, 2004).

Os custos marginais do insumo ambiental devem refletir as variações nos benefícios econômicos auferidos pelos usuários de água na curva de oferta do bem. Desse modo, procurou-se evidenciar como mudanças no insumo ambiental (variável representativa do serviço ecossistêmico) alteram os custos de tratamento. Ou seja, qual a magnitude do impacto da mudança na qualidade ambiental sobre o custo de tratamento na bacia de captação. Freeman \& Harrington (1990) sugeriram uma especificação visando capturar a contribuição da produção e do consumo do bem comercializado no bem-estar social, cuja variação esteve associada com a produção $\mathrm{Q}$, podendo ser calculada diretamente da curva de demanda e de custo se os níveis de produção final e inicial $\mathrm{Q}^{0} \mathrm{e} \mathrm{Q}^{1}$ forem conhecidos. Graficamente, a mudança no bem-estar é representada pela área entre as curvas dos custos antes e depois da mudança da qualidade ambiental (Figura 1).

$\mathrm{P}_{\mathrm{Q}}(\mathrm{Q})$ é a curva de demanda inversa e $\mathrm{CM}_{\mathrm{Q}}\left(\mathrm{S}^{0}\right)$ e $\mathrm{CM}_{\mathrm{Q}}\left(\mathrm{S}^{1}\right)$ indicam as curvas de custo marginal para a firma como uma função de Q e S. A distribuição dos ganhos entre consumidores e produtores é representada graficamente pela Figura 1. Assim, os consumidores ganham as áreas $w+v$, enquanto os produtores perdem a área $w$, porém ganham a área $u$.

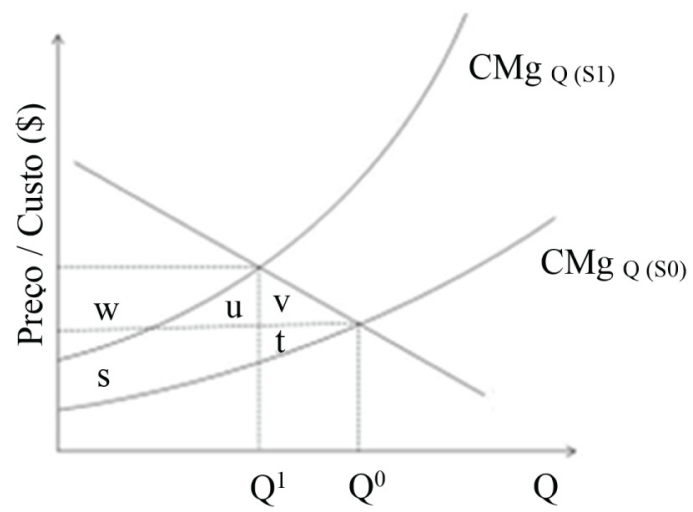

Figura 1. Medidas de bem-estar econômico. Figure 1. Measures of economic welfare. 
O benefício líquido total corresponde à área $u+v$. As referidas medidas podem ser determinadas por meio de integração apropriada. Visando simplificar os procedimentos e cálculos, a determinação do valor econômico foi realizada com base na perspectiva do consumidor de água.

Assim, elaborou-se um procedimento de valoração econômica que permitiu mensurar o impacto da variação da qualidade ambiental sobre o bem-estar econômico dos consumidores de água do sistema de abastecimento público. A variação no excedente econômico total forneceu uma medida do valor econômico do serviço de proteção da qualidade hídrica. Para a validação das formulações elaboradas, assumiu-se que a perda do serviço de provisão de qualidade hídrica, oriunda de alterações na base florestal da bacia, gera um custo social aos consumidores de água.

Para implementação do modelo conceitual descrito anteriormente obtiveram-se as elasticidades preço da demanda e da oferta de água nos sistemas produtores de Pompermayer (2012). A interação entre as elasticidades da oferta e da demanda determinaram, respectivamente, o deslocamento da oferta em virtude de uma mudança na qualidade ambiental e a magnitude do custo social que atinge os consumidores de água.

O custo social decorrente das mudanças na cobertura florestal da bacia hidrográfica é uma aproximação do valor do serviço de proteção da qualidade hídrica. Assim, procurou-se dimensionar a magnitude do custo social da degradação da qualidade hídrica a partir de formulação sugerida por Santana \& Khan (1992), conforme ilustrado na Figura 2.

Conforme ilustrado na Figura 2, uma mudança da curva de oferta de $S_{0}$ para $S_{1}$ significa que mais de um produto será oferecido no mercado ao mesmo nível de preço $\mathrm{P}_{0}$. Nesse preço diz-se que houve um aumento da oferta de $Q_{0}$ para $Q_{2}$. O resultado final da inovação tecnológica é uma redução dos custos unitários de produção e no preço do produto $\left(\right.$ de $\mathrm{P}_{0}$ para $\left.\mathrm{P}_{1}\right)$ e um aumento da oferta de mercado de $\mathrm{Q}_{0}$ para $\mathrm{Q}_{1}$.

Santana \& Khan (1992) propõem que mudança no recurso ambiental desloca a curva de oferta de $S_{1}$ para $\mathrm{S}_{0}$ (Figura 2). Desse modo, o novo equilíbrio ocorre no ponto A, no qual preços maiores e quantidades menores são praticados em comparação com a situação inicial de equilíbrio. No caso estudado, o custo social resultante da degradação da qualidade hídrica é representado pela

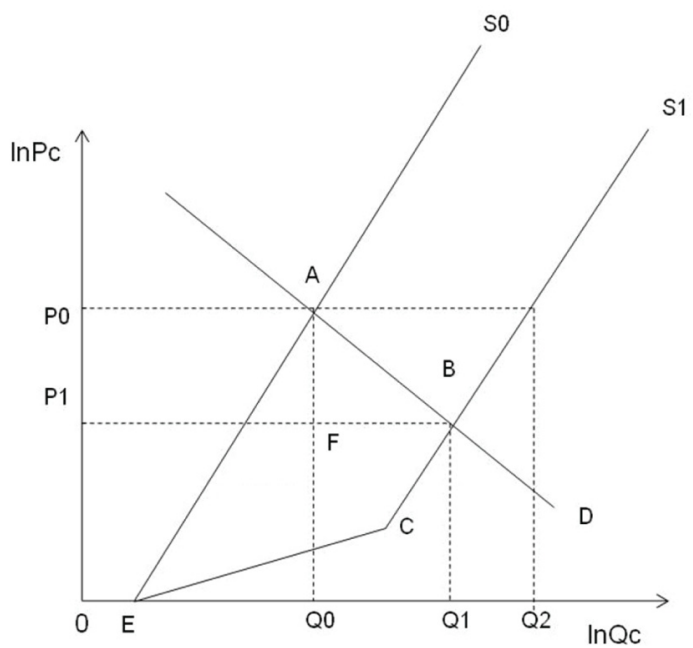

Figura 2. Benefício social resultante de mudança tecnológica.

Figure 2. Social benefit resulting from technological change.

área formada pelo polígono $\mathrm{ABCE}$, entre as duas curvas de oferta $\left(S_{0}\right.$ e $\left.S_{1}\right)$ e abaixo da curva de demanda (D).

Os parâmetros $\mathrm{P}_{0}$ e $\mathrm{Q}_{0}$ são os valores de preço e quantidade de água comercializada no equilíbrio, após mudança no recurso ambiental. Já os parâmetros $\mathrm{P}_{1}$ e $\mathrm{Q}_{1}$ correspondem a preço e quantidade comercializada no equilíbrio, antes da variação no insumo ambiental. Os parâmetros $\eta$ e $\varepsilon$ são, respectivamente, as elasticidades da demanda e da oferta em relação ao preço. $Q_{2}$ é igual à quantidade média de água comercializada no período analisado. Algebricamente, a determinação da área $\mathrm{ABCE}$, assim como da parcela dos custos que atinge os consumidores e produtores podem ser obtidas pelas Equações 1-3.

Custo social total $(\mathrm{CT})=0,5 \mathrm{KP}_{0} \mathrm{Q}_{0}(1+\mathrm{Z \eta})$

Custo social do consumidor $(\mathrm{CC})=\mathrm{ZP}_{0} \mathrm{Q}_{0}(1+0,5 \mathrm{Z \eta})$

Custo social do Produtor $(\mathrm{CP})=\mathrm{CT}-\mathrm{CC}$

Conforme a Equação 4, o parâmetro Ké o deslocador da curva de oferta, medido pela mudança proporcional na produção dividida pela elasticidade da oferta $(\varepsilon)$.

$\mathrm{K}=\left|\left(1-\mathrm{Q}_{0} / \mathrm{Q}_{2}\right) / \varepsilon\right|$

Santana \& Khan (1992) sugerem para a obtenção de Z, a partir da Equação 5:

$\mathrm{Z}=\mathrm{K} \varepsilon /(\eta+\varepsilon)$ 
Para efeitos de análise, considerou-se a hipótese de que quanto mais inelástica a demanda em relação ao preço, em comparação com a oferta, maior a parcela de custo social que recai sobre os consumidores de água. A partir das formulações apresentadas estimaram-se as variações no nível de bem-estar dos consumidores de água nas duas categorias de usuários (normal e popular).

\subsection{Fonte de dados}

Nas estimativas dos custos sociais da degradação da qualidade hídrica no Distrito Federal utilizaram-se dados de séries temporais mensais da produção e comercialização da água no sistema de abastecimento da CAESB, referentes ao período de 2003 a 2008. Mais especificamente, a quantidade de água comercializada, em metros cúbicos por mês, a receita total da água comercializada, em reais por metro cúbico, e o preço médio efetivamente cobrado pela água comercializada. O preço foi determinado levando-se em conta que os consumidores estão sujeitos a um regime tarifário em blocos crescentes, no qual os dados das quantidades consumidas e das receitas da água comercializada estão desagregados em oito faixas de consumo.

Os dados do sistema de abastecimento público da área de estudo estão desagregados em duas categorias de consumidores: a residencial normal e a residencial popular. Tal classificação é utilizada pela CAESB para a aplicação das tarifas mensais utilizadas para cobrança dos serviços de água e esgoto. As unidades de consumo residenciais são enquadradas nas referidas categorias, tendo em vista o disposto no artigo $7^{\circ}$, do decreto n. 20.658, de 30 de setembro de 1999 (Distrito Federal, 1999), que estabelece pontuação e classificação conforme as características físicas das residências. No período analisado, os valores do preço médio da água comercializada foram corrigidos com base no mês de dezembro de 2008, utilizando valores mensais do Índice de Preços ao Consumidor (IGP - M), calculados pela Fundação Getúlio Vargas - FGV.
Nas duas categorias de consumidores de água do Distrito Federal, o custo social da degradação da qualidade hídrica foi mensurado. Para tanto, utilizaram-se as elasticidades da demanda de água em relação ao preço ( $\eta$ ) bem como a resposta do monopolista em relação ao preço percebido pelos consumidores de água do sistema de abastecimento $(\varepsilon)$. Tais parâmetros foram estimados a partir da derivação da curva de demanda e de uma aproximação da curva de oferta de água nos sistemas de abastecimento, detalhadas em Pompermayer (2012). A interação entre os parâmetros da oferta e da demanda (elasticidades-preço da oferta e da demanda) determinam, respectivamente, o deslocamento da oferta em virtude de uma mudança na qualidade ambiental e a magnitude do custo social que atinge os consumidores de água.

No intuito de conciliar os horizontes de ambos os parâmetros adotados, a análise abrange dados de séries temporais de janeiro de 2003 a dezembro de 2008. Ou seja, a elasticidade da demanda corresponde ao período de janeiro de 2001 a dezembro 2008, enquanto a elasticidade da oferta corresponde ao período de janeiro de 2003 a dezembro de 2010. Como não há discrepâncias nas quantidades demandadas e ofertadas entre os períodos, devido ao curto horizonte de tempo, assumiu-se que não existem variações acentuadas nesse parâmetro.

\section{RESULTADOS E DISCUSSÕES}

O custo social da degradação da qualidade hídrica foi mensurado nas duas categorias de consumidores de água do Distrito Federal. A interação entre os parâmetros da oferta e da demanda (elasticidades-preço da oferta e da demanda) determinam a magnitude do custo social que atinge os consumidores de água. Na Tabela 1, estão apresentadas as elasticidades da oferta e da demanda em relação ao preço, bem como a quantidade média de água comercializada nas duas categorias de usuários residenciais, no período de 2001 a 2008.

Tabela 1. Parâmetros para as duas classes de consumidores, quantidade média comercializada $\left(\mathrm{m}^{3} / \mathrm{mê}^{\mathrm{s}}\right)$ e elasticidade-preço.

Table 1. Parameters for the two classes of consumers, average quantity sold ( $\left.\mathrm{m}^{3} / \mathrm{month}\right)$ and price elasticity. 
De modo geral, a perda da cobertura florestal resulta em impactos na forma de custo social, comprometendo os benefícios gerados pela comercialização da água. Esses custos recaem totalmente sobre a população usuária de água. Isso porque, na área de estudo, a demanda de água apresentou-se muito inelástica em relação ao preço. Como a oferta é bem menos inelástica que o preço, o produtor praticamente não é afetado pelo custo social.

Na Tabela 2 estão determinados os valores médios anuais do deslocador proporcional da curva de oferta (K), em termos percentuais, do custo social atribuído aos consumidores de água da categoria residencial popular. Os resultados mostram, ainda, a participação do custo social da degradação de serviço ambiental na despesa de água dos consumidores. Em média, o custo social anual da degradação da qualidade hídrica foi estimado em 7 milhões de reais, no período de janeiro de 2003 a dezembro de 2008, atingindo seu valor máximo em 2004, equivalente a 11,4 milhões de reais.

Na categoria popular, o custo social da redução do serviço ambiental no período estudado comprometeu, em média, 8,9\% dos benefícios proporcionados pelo volume de água comercializado nessa categoria. Também a Tabela 2 registrou um deslocamento médio da curva de oferta de aproximadamente $12,4 \%$. No período analisado, o comprometimento dos benefícios da arrecadação com comercialização da água, atribuído aos consumidores da categoria popular, em termos absolutos, pode ser visualizado na Figura 3.

Tabela 2. Estimativa do custo social da degradação da qualidade hídrica e seus impactos sobre os consumidores de água da categoria residencial popular ( $\mathrm{R} \$$ de dezembro de 2008).

Table 2. Estimated social cost of degradation and its impacts on water users of the popular residential category (R\$ of December 2008).

\begin{tabular}{|c|c|c|c|c|}
\hline Período & $\begin{array}{c}\text { Deslocador oferta } \\
\text { K (\%) }\end{array}$ & $\begin{array}{c}\text { Custo social } \\
\text { CC (R\$) [a] }\end{array}$ & $\begin{array}{c}\text { Receita total } \\
\text { RT (R\$) [b] }\end{array}$ & {$[\mathbf{a}] /[\mathbf{b}](\%)$} \\
\hline 2003 & 18,25 & $7.018 .088,38$ & $52.475 .180,36$ & 13,37 \\
\hline 2004 & 12,16 & $11.396 .900,77$ & $107.593 .621,71$ & 10,59 \\
\hline 2005 & 7,09 & $3.147 .187,16$ & $65.206 .391,01$ & 4,83 \\
\hline 2006 & 6,63 & $3.503 .948,93$ & $82.749 .367,52$ & 4,23 \\
\hline 2007 & 13,29 & $7.733 .688,48$ & $86.773 .597,29$ & 8,91 \\
\hline 2008 & 16,83 & $9.253 .752,58$ & $82.615 .521,56$ & 11,20 \\
\hline Média & 12,37 & 7.008.927,72 & $79.568 .946,57$ & 8,86 \\
\hline
\end{tabular}

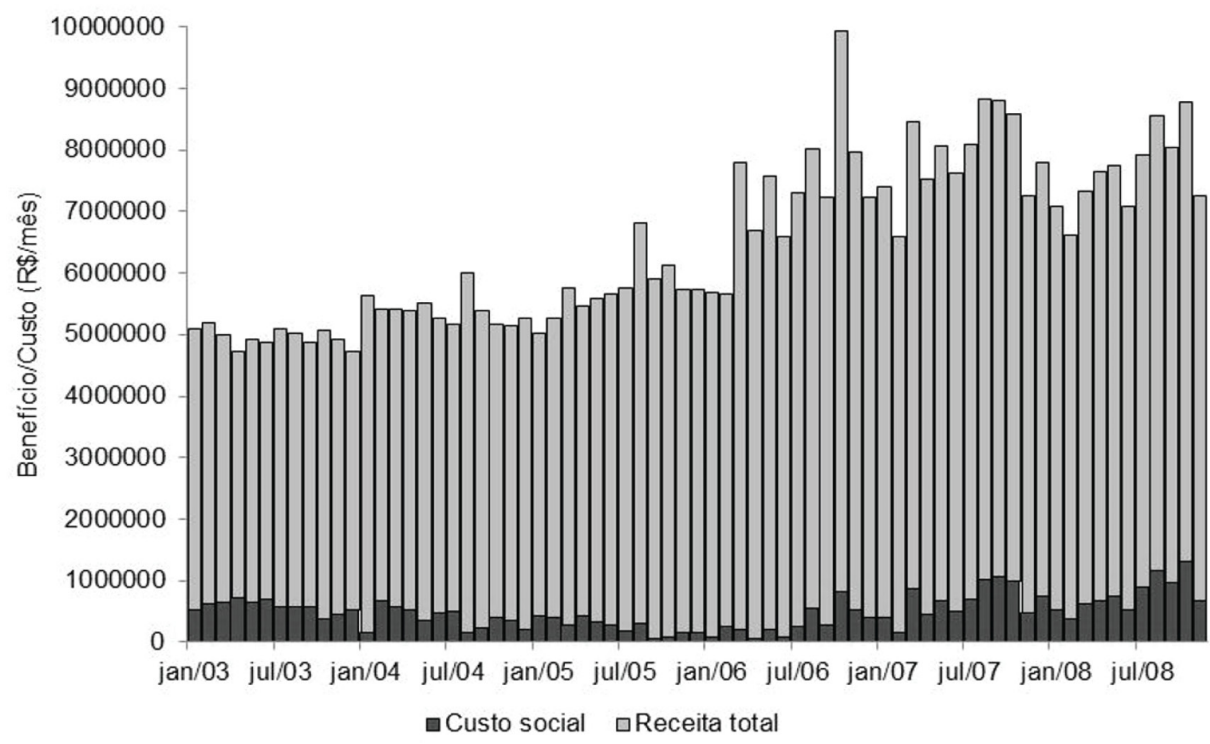

Figura 3. Perdas dos benefícios da comercialização da água na categoria popular. Figure 3. Loss of benefits from commercialization of water in popular category. 
Observa-se que as maiores perdas dos benefícios da comercialização da água devidas ao custo social da degradação da qualidade hídrica ocorreram entre julho de 2007 a outubro de 2008. Por outro lado, as menores perdas de benefícios são verificadas entre agosto de 2005 a julho de 2006.

Apresentam-se na Tabela 3 os valores médios anuais do deslocador proporcional da curva de oferta (K) em termos percentuais e o custo social anual atribuído aos consumidores de água na categoria residencial normal. Os resultados mostram o comprometimento do benefício total da comercialização da água pelo custo social da degradação de serviço ambiental atribuído aos usuários da categoria residencial normal. Nessa categoria, em média, o custo social da degradação da qualidade hídrica foi estimado em 12,9 milhões de reais no período de janeiro de 2003 a dezembro de 2008, atingindo seu valor máximo em 2004 e 2008, o equivalente a 19,2 milhões de reais. Do lado do consumidor, isso significa que o custo social contribuiu, em média, com $6,78 \%$ das despesas de água na categoria normal. Evidenciou-se um fator deslocador médio da curva de oferta $(\mathrm{K})$ equivalente a $13 \%$, no período estudado.

A Figura 4 ilustra o comprometimento dos benefícios da arrecadação com comercialização da água decorrente dos custos sociais atribuídos aos consumidores da classe residencial normal. Nessa categoria visualizam-se menores impactos dos custos sociais sobre a população

Tabela 3. Estimativa do custo social da degradação e seus impactos sobre os consumidores de água da categoria residencial normal (R\$ de dezembro de 2008).

Table 3. Estimated social cost of degradation and its impact on consumers of water from normal residential category ( $\mathrm{R} \$$ of December 2008).

\begin{tabular}{ccccc} 
Período & $\begin{array}{c}\text { Deslocador oferta } \\
\text { K (\%) }\end{array}$ & $\begin{array}{r}\text { Custo social } \\
\text { CC }(\mathbf{R} \$ \mathbf{a}]\end{array}$ & $\begin{array}{r}\text { Receita total } \\
\text { RT }(\mathbf{R} \$)[\mathbf{b}]\end{array}$ & {$[\mathbf{a}] /[\mathbf{b}](\%)$} \\
\hline 2003 & 12,76 & $8.826 .609,34$ & $127.364 .456,20$ & 6,93 \\
\hline 2004 & 14,48 & $19.260 .760,74$ & $256.970 .981,37$ & 7,50 \\
\hline 2005 & 9,58 & $8.264 .748,33$ & $166.979 .901,67$ & 4,95 \\
\hline 2006 & 10,79 & $10.545 .380,30$ & $190.798 .939,02$ & 5,53 \\
\hline 2007 & 11,62 & $11.493 .915,72$ & $197.558 .409,17$ & 5,82 \\
\hline 2008 & 18,64 & $19.224 .376,01$ & $192.900 .974,49$ & 9,97 \\
\hline Média & 12,98 & $12.935 .965,07$ & $188.762 .276,99$ & 6,78 \\
\hline
\end{tabular}

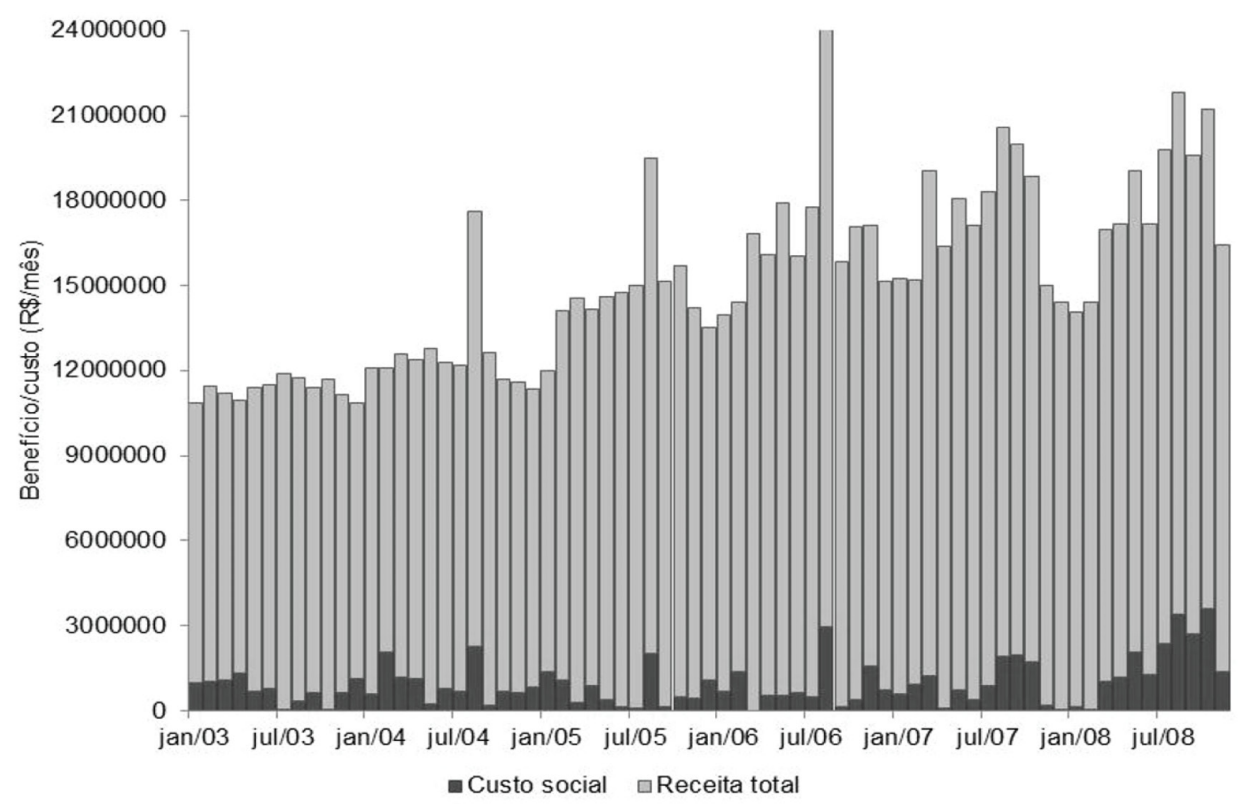

Figura 4. Perdas dos benefícios da comercialização da água na categoria normal.

Figure 4. Loss of benefits from commercialization of water in the normal category. 
usuária de água comparativamente à categoria popular. Ocorre que na categoria residencial normal a demanda de água apresentou-se menos inelástica em relação a preço. De modo geral, um maior comprometimento do bem-estar dos consumidores de água do sistema de abastecimento foi percebido, principalmente, em fevereiro de 2004, em setembro de 2008, em julho de 2008 e em agosto de 2008, quando o custo social representou: $20,9 \%, 20,5 \%, 18,5 \%$ e $16 \%$ das despesas de água dos consumidores, respectivamente.

A perda da qualidade hídrica, refletida nos custos de tratamento de água, resultou em impactos na forma de custo social, comprometendo os benefícios gerados pela comercialização da água. Esses custos recaíram totalmente sobre a população das categorias usuárias de água. Tal resultado é influenciado pela magnitude das elasticidades estimadas. Tendo em vista que a demanda é mais inelástica que as variações de preço em relação à oferta, os consumidores representam o segmento mais penalizado pelo custo social. Como a oferta de água é bem menos inelástica a preço em relação à demanda de água, o produtor praticamente não é afetado pelo custo social da degradação da qualidade hídrica. De um lado, os benefícios da conservação correspondem aos ganhos dos consumidores pela economia proporcionada. Por outro lado, o conhecimento da dimensão de valor e da proporção de seus impactos sobre a sociedade proporciona aos agentes envolvidos na alocação dos usos dos recursos ambientais ganhos de percepção e de motivação.

\section{CONCLUSÕES}

A abordagem de valoração econômica fundamentada no método da produtividade marginal, além de estimar a dimensão dos custos que recaem sobre a sociedade, permitiu identificar o segmento econômico mais atingido pelos impactos da degradação da qualidade hídrica. Essa informação pode ser útil para o delineamento de políticas e instrumentos específicos para internalizar os custos da degradação ambiental em mecanismos formais de pagamento por serviços ambientais. As medidas das variações nos níveis de bem-estar econômico forneceram uma estimativa do custo social da perda do serviço ambiental de qualidade hídrica.

Os custos sociais atingiram na totalidade os consumidores de água do sistema de abastecimento público. Já a empresa de saneamento, representativa do segmento dos produtores, praticamente não sofreu os impactos da degradação da qualidade hídrica, dada sua estrutura monopolista. Na categoria popular, o custo social representou $8,9 \%$ da despesa total de água dos consumidores, no período de janeiro de 2003 a dezembro de 2008. Na categoria normal, o custo social representou o equivalente a $6,8 \%$ da despesa total de água dos consumidores naquele período. Apesar da diferença sutil entre as magnitudes da elasticidade-preço, a perda de benefícios decorrente dos custos da degradação do serviço ambiental de qualidade hídrica recaiu em maior proporção sobre a população da classe residencial popular. Tal evidência foi pertinente com as expectativas teóricas, visto que nessa categoria a demanda apresentou resposta mais inelástica a preço em comparação com a categoria normal.

A magnitude dos custos sociais da degradação da qualidade hídrica deveria ser avaliada sob uma perspectiva econômica global, pois atinge diferentes segmentos da sociedade. Idealmente, os mecanismos voltados para a conservação, tais como valores estipulados para os pagamentos por serviços ambientais, deveriam ser proporcionais aos benefícios da conservação ambiental.

\section{STATUS DA SUBMISSÃO}

Recebido: 25 set., 2014

Aceito: 22 dez., 2015

AUTOR(ES) PARA CORRESPONDÊNCIA

\section{Alexandre Nascimento de Almeida}

Faculdade UnB de Planaltina - FUP, Universidade de Brasília - UnB, Área Universitária n. 1, Vila Nossa Senhora de Fátima, CEP 73300-000, Planaltina, DF, Brasil e-mail: alexalmeida@unb.br

\section{REFERÊNCIAS}

Brown TC, Hobbins MT, Ramirez JA. Spatial distribution of water supply in the coterminous United States. Journal of the American Water Resources Association 2008; 44(6): 14741487. http://dx.doi.org/10.1111/j.1752-1688.2008.00252.x.

Companhia de Planejamento do Distrito Federal CODEPLAN. Anuário estatístico do Distrito Federal [online]. Brasilia: SEDUMA; 2010. [citado em 2014 Jul. 01]. Diponível em: http://www.codeplan.df.gov.br/ 
Cretaz AL, Barten PK. Land use effects on streamflow and water quality in the northeastern United States. Boca Raton: CRC Press; 2007.

Distrito Federal. Decreto No 20.658, 30 de setembro de 1999, que regulamenta a Lei No. 442, de 10 de maio de 1993, que dispõe sobre a classificação de tarifas dos serviços de água e esgotos do distrito federal e dá outras providências. Diário Oficial do Distrito Federal, Brasília, DF (1999 set.). [citado em 2014 Jul. 01]. Diponível em: http://www.caesb.df.gov. br/_conteudo/Legislacao/Decretos/Decreto20658.asp

Ellis GM, Fisher AC. Valuing the environment as input. Journal of Environmental Management 1987; 25: 149-156.

Elsin YK, Kramer RA, Jenkins WA. Valuing drinking water provision as an ecosystem service in the Neuse River Basin. Journal of Water Resources Planning and Management 2010; 136(4): 474-482. http://dx.doi.org/10.1061/(ASCE) WR.1943-5452.0000058.

Ernst C, Gullick R, Nixon K. Protecting the source: conserving forests to protect water. American Water Works Association 2004; 35(5): 4-7.

Ernst C. Protecting the source: land conservation and the future of America's drinking water. Washington: Trust for Public Land; 2004.

Figueroa EB, Pasten RC. Forest and water: the value of native temperate forests in supplying water for human consumption: a comment. Ecological Economics 2008; 67(2): 153-156. http://dx.doi.org/10.1016/j.ecolecon.2008.07.003.

Freeman AM III, Harrington W. Measuring welfare values of productivity changes. Southern Economic Journal 1990; 56(4): 892-904. http://dx.doi.org/10.2307/1059879.

Freeman J, Madsen R, Hart K. Statistical analysis of drinking water treatment plant costs, source water quality, and land cover characteristics [online]. Washington, D.C.: U.S Environmental Protection Agency; 2008. [citado em 2014 Ago. 17]. Disponível em: http://wren.palwv.org/ library/documents/landnwater_9_2008_Whitepaper.pdf

Hosking S, Preez M. The valuation of water for conservation projects in South Africa. Development Southern Africa 2004; 21(2): 385-398. http://dx.doi.org/10.1080/03768 35042000219604 .

Lynne GD, Conroy P, Prochaska FJ. Economic value of marsh areas for marine production processes. Journal of
Environmental Economics and Management 1981; 8(2): 175-186. http://dx.doi.org/10.1016/0095-0696(81)90006-1.

Nunez D, Nahuelhual L, Oyarzun C. Forests and water: The value of native temperate forests in supplying water for human consumption. Ecological Economics 2006; 58(3): 606-616. http://dx.doi.org/10.1016/j.ecolecon.2005.08.010.

Page A, Knowler D, Fraser S. Valuing the water purification/ filtration service of temperate coastal rainforests in southwestern british columbia: a stochastic production function approach. In: AERE Summer Conference 2011; 2011; Seattle. Canadá: Simon Fraser University; 2011.

Pattanayak SK, Kramer R. Worth of watersheds: a producer surplus approach for valuing drought control in Eastern Indonesia. Environment and Development Economics 2001; 6(1): 123-146. http://dx.doi.org/10.1017/ S1355770X01000079.

Pindyck RS, Rubinfeld D. Microeconomia. 5. ed. São Paulo: Prentice Hall; 2002. 710 p.

Pizaia MG. Regulação do uso da água, identificação da tarifa econômica de equilíbrio [tese]. Florianópolis: Universidade Federal de Santa Catarina; 2004.

Pompermayer RS. Valoração econômica do serviço ambiental de proteção da qualidade hídrica [tese]. Brasília: Universidade de Brasília; 2012.

Reis LVS. Cobertura vegetal e custo do tratamento de águas em Bacias Hidrográficas de abastecimento público: caso do manancial do município de Piracicaba [tese]. Piracicaba: Escola Superior de Agricultura Luiz de Queiroz, Universidade de São Paulo; 2004.

Santana AC, Khan AS. Custo social da depredação florestal no Pará: o caso da castanha-do-Brasil. Revista de Economia e Sociologia Rural 1992; 30(1): 253-269.

Sistema Ibero Americano de Información sobre el Agua - SIAGUA. Brasília: SIAGUA; 2008. [citado em 2014 Ago. 19]. Disponível em: http://www.siagua.org/

World Bank. How much is an ecosystem worth? Assessing the economic value of conservation [online]. Washington: World Bank; 2004. [citado em 2014 Ago. 19]. Disponível em: http://jncc.defra.gov.uk/pdf/BRAG_SE_PagiolaetalHowMuchIsAnEcosystemWorth(World BankIUCNReport).pdf 